\title{
Praktik Dokter Terkait Perilaku Merokok Pasien
}

\author{
Pujianto* Hasbullah Thabrany* Budi Hidayat* Michael Ong** Fitriah***
}

\begin{abstract}
Abstrak
Kini Indonesia berada pada awal tahap kedua epidemi tembakau dengan prevalensi perokok pada penduduk berumur di atas 10 tahun mencapai $23,7 \%$. Dalam memerangi epidemi tembakau, dokter memegang peran kunci membantu pasien berhenti merokok. Untuk mengetahui praktik dokter terkait perilaku merokok pasiennya telah dilakukan survei di Jakarta dengan sampel 96 dokter yang dipilih secara acak. Hasil survei menunjukkan hanya 1 dari 50 dokter yang merokok setiap hari (2,1\%). Pengetahuan dan sikap dokter tentang merokok pada umumnya sangat baik, yaitu $93,8 \%$ mengetahui dampak negatif perokok pasif, 84,4\% mengetahui bahwa rokok dengan kadar tar/ nikotin rendah tetap membahayakan, 93,8\% setuju menjadikan dokter sebagai role model perilaku tidak merokok, dan 95,8\% setuju dengan kondisi bebas asap rokok di rumah sakit. Namun, dokter yang tidak selalu menanyakan kebiasaan merokok pasien cukup tinggi $(66,7 \%)$ dan dokter yang tidak selalu memberikan nasehat kepada pasien untuk berhenti merokok (38\%). Analisis regresi logistik menemukan bahwa dokter yang bekerja di bagian jantung dan paru berpeluang 28,4 kali lebih besar untuk menanyakan kebiasaan merokok pasien daripada dokter yang bekerja di bagian penyakit dalam. Penulis menyarankan agar dilaksanakan pendidikan dokter berkelanjutan tentang bahaya merokok dan pengendalian merokok.
\end{abstract}

Kata kunci : Dokter, pengetahuan, sikap, perilaku, tembakau

\begin{abstract}
Indonesia is in the second phase of tobacco epidemic shown by $23,7 \%$ of people age $10+$ years are smoking. In tobacco control programs, physicians play significant roles. To know how Indonesian physicians behave in facing smoking habits, a survey to 96 practicing physicians in three clinical departments has been undertaken in Jakarta. The survey identified that only one in 50 (2,1\%) physicians smoke daily. As high as $93.8 \%$ physicians know about negative impact of passive smokers, $84.4 \%$ know that low tar/nicotine has significant impact on health, $93.8 \%$ agree that physicians should be one of the role model to smoking cessation, and $95.8 \%$ agree on free smoke environment in all hospital premises. However, $66.7 \%$ physicians did not regularly asking smoking behavior of their patients and $38 \%$ did not advice patients to stop smoking. Logistic regression produce 28.4 times higher probability of physicians in Lung and Heart Clinic to ask smoking behavior of their patients as compared to physicians in Internal Medicines. The authors suggest to introduce a special continuing medical education on smoking and smoking cessation of practicing physicians.
\end{abstract}

Key words : Physician, knowledge, attitude, practice, tobacco

*Departemen Administrasi Kebijakan Kesehatan Fakultas Kesehatan Masyarakat Universitas Indonesia, Gd. F Lt. 1 FKM UI, Kampus Baru UI Depok 16424 (e-mail: puji_fkm@ui.ac.id)

**Division of General Internal Medicine and Health Service Research, Department of Medicine UCLA, 911 Broxton Avenue 1st Floor Los Angeles CA 90024

${ }^{* * *}$ Fakultas IImu Keperawatan Universitas Indonesia, FIK UI Kampus Baru UI Depok 16424 
Berdasarkan fakta prevalensi perokok dan prevalensi penyakit terkait rokok, dapat disimpulkan bahwa Indonesia berada pada awal tahap kedua epidemi tembakau. ${ }^{1}$ Epidemi tersebut ditandai dengan karakteristik (a) prevalensi perokok laki-laki dari berbagai kelas sosial ekonomi yang tinggi, (b) angka perempuan perokok relatif rendah, tetapi meningkat cepat dan (c) tidak ada kegiatan pengendalian tembakau yang baik. Kesimpulan itu didukung hasil Riset Kesehatan Dasar atau Riskesdas tahun 2007 yang menunjukkan 23,7\% penduduk berumur 10 tahun keatas merokok setiap hari. ${ }^{2}$ Angka tersebut lebih tinggi dari prevalensi perokok umur yang sama di Amerika (20,9\%) tetapi lebih rendah dari prevalensi perokok umur yang sama di China $(31 \%) .{ }^{3}$ Risiko yang ditimbulkan lebih besar karena $85,4 \%$ perokok Indonesia merokok di dalam rumah ketika sedang bersama-sama anggota rumah tangga lain. ${ }^{2} \mathrm{Hal}$ itu menyebabkan $>70 \%$ anak Indonesia terpajan asap rokok dan menanggung risiko penyakit akibat rokok. Selain itu, rokok telah menggerogoti sumber keuangan rumah tangga miskin yang rata-rata menyita $12,4 \%$ belanja rumah tangga, mengorbankan gizi, kesehatan, dan pendidikan keluarga. ${ }^{4}$

Prevalensi merokok di kalangan laki-laki sangat tinggi, rata-rata salah satu anggota rumah tangga ada yang merokok, sementara di sekolah, guru laki-laki sering terlihat merokok. Dalam berbagai pertemuan sosial di pedesaan, upacara kelahiran, perkawinan dan upacara keagamaan lain disediakan rokok. Pada acara kematian, masyarakat berkumpul di rumah duka menghabiskan malam berdoa dan berbagi makan, minum kopi, dan merokok. Rokok juga sering digunakan sebagai pertanda solidaritas atau penghargaan kepada teman, pengunjung, atau tamu dalam budaya Indonesia, menolak pemberian rokok dipandang tidak sopan. ${ }^{1}$

Sama seperti di China, ${ }^{5}$ di Indonesia intervensi menghentikan kebiasaan merokok di kalangan profesional kurang dipasarkan. Pelayanan henti merokok dalam sistem pelayanan kesehatan masih tergolong langka. Padahal, dokter memegang peran kunci dalam membantu pasien berhenti merokok. Intervensi sederhana seperti memberi nasehat agar pasien berhenti merokok dan intervensi yang lebih intensif seperti konseling atau pemberian terapi obat kecanduan meningkatkan peluang keberhasilan program henti merokok. Dokter juga dapat berperan sebagai role model perilaku sehat dengan tidak merokok. ${ }^{3}$ Studi di China menemukan bahwa dokter yang tidak pernah merokok (never smoke) lebih mungkin menasehati pasien untuk berhenti merokok daripada dokter perokok (current smoker). ${ }^{3}$ Dokter bukan perokok lebih mungkin melakukan konseling anti-merokok daripada dokter perokok. ${ }^{6}$

Survei pendahuluan untuk mengetahui KAP dokter praktik dari tiga kelompok dokter spesialisasi paru, jan- tung dan penyakit dalam yang paling banyak berhubungan dengan kasus terkait tembakau yang tinggal di Jakarta.

\section{Metode}

Penelitian ini merupakan penelitian survei dengan populasi dokter dari tiga spesialisasi tersebut diatas yang keanggotaannya tercatat di perhimpunan spesialis terkait cabang Jakarta. Jumlah seluruh populasi adalah 619 orang dokter spesialis, terdiri dari dokter spesialis paru 195 orang, dokter spesialis jantung 180 orang, dan dokter spesialis penyakit dalam 244 orang. Pengambilan sampel dilakukan secara acak menggunakan random numbers generator pada perangkat lunak Microsoft excell. Setelah sampel ditetapkan, pengumpul data menghubungi dokter calon responden sesuai dengan urutan angka random yang dihasilkan mulai dari angka random urutan pertama, kedua, ketiga, dan seterusnya. Apabila dokter yang terpilih menolak diwawancara, dilanjutkan dengan angka random urutan berikutnya hingga diperoleh 96 responden. Hingga terkumpul 96 dokter yang bersedia menjadi responden, ada 65 orang dokter, yang dengan berbagai alasan, menolak diwawancara sebagai responden. Pengumpulan data lapangan dilakukan antara bulan Juli 2008 hingga Juni 2009.

\section{Hasil}

\section{Deskripsi Sampel}

Seluruh responden bekerja di 31 rumah sakit di Jakarta. Terlihat bahwa sebagian besar responden adalah laki-laki $(77,1 \%)$, proporsi responden yang tidak pernah

Tabel 1: Karakteristik Responden dalam Survei

\begin{tabular}{|c|c|c|}
\hline Karakteristik Responden & Katagori & Persen \\
\hline \multirow[t]{2}{*}{ Jender } & Laki-laki & 77,1 \\
\hline & Perempuan & 22,9 \\
\hline \multirow[t]{4}{*}{ Kebiasaan Merokok } & Tidak pernah & 81,2 \\
\hline & Pernah & 15,6 \\
\hline & Setiap hari & 2,1 \\
\hline & Tidak setiap hari & 1,0 \\
\hline \multirow[t]{4}{*}{ Umur (tahun) } & 30-39 tahun & 17,4 \\
\hline & 40-49 tahun & 23,9 \\
\hline & 50-59 tahun & 25,0 \\
\hline & $\geq 60$ tahun & 33,7 \\
\hline \multirow[t]{4}{*}{ Pengalaman Praktik } & $<5$ tahun & 25,0 \\
\hline & 5-9 tahun & 13,5 \\
\hline & 10-19 tahun & 22,9 \\
\hline & $\geq 20$ tahun & 38,5 \\
\hline \multirow[t]{3}{*}{ Bagian (Tempat Praktik) } & $\overline{\text { Paru }}$ & 24,0 \\
\hline & Jantung & 24,0 \\
\hline & Penyakit dalam & 52,1 \\
\hline \multirow[t]{3}{*}{ Pendidikan } & PPDS (Resident) & 9,4 \\
\hline & Spesialis & 53,1 \\
\hline & Spesialis konsultan & 37,5 \\
\hline \multirow[t]{5}{*}{ Jumlah Pasien per hari } & $<5$ & 5,2 \\
\hline & $5-10$ & 15,6 \\
\hline & $11-20$ & 22,9 \\
\hline & $21-30$ & 26,0 \\
\hline & $>30$ & 30,2 \\
\hline
\end{tabular}


Tabel 2. Pernyataan Dokter Tentang Pengetahuan, Sikap, dan Perilaku Dokter Terkait Merokok

\begin{tabular}{lll}
\hline Pengetahuan & Katagori & Persen \\
\hline Bahaya kesehatan perokok pasif kecil/tak ada & Tidak setuju & 93,8 \\
& Setuju & 6,2 \\
Rokok berkadar tar/nikotin rendah kurang berbahaya bagi kesehatan & Tidak setuju & 84,4 \\
Sikap & Setuju & 15,5 \\
Dokter bertanggung jawab role model perilaku tidak merokok & Tidak setuju & 6,3 \\
Di semua ruangan di RS dilarang merokok & Setuju & 93,8 \\
& Tidak setuju & 4,2 \\
Praktik & Setuju & 95,8 \\
Bertanya tentang status merokok pasien & & 8,3 \\
& Jarang & 32,3 \\
& Hanya pada pasien yang sakit terkait merokok & 26,0 \\
Menasehati pasien berhenti/kurangi jumlah rokok & Sering & 33,3 \\
& Selalu & 2,0 \\
& Tidak Pernah & 5,2 \\
& Kadang-kadang & 20,8 \\
\end{tabular}

Tabel 3. Hasil Estimasi Model Regresi Logistik

\begin{tabular}{|c|c|c|c|}
\hline Variabel & Beta & $\operatorname{Exp}(B)$ & (SE) \\
\hline Pengalaman praktik $>=20$ tahun & 0,693 & 2,001 & $(0,728)$ \\
\hline Pendidikan Doktor/spesialis konsultan & $-0,026$ & 0,975 & $(0,520)$ \\
\hline Jumlah pasien $>20$ per hari & 0,896 & 0,449 & $(0,592)$ \\
\hline Pernah merokok & $-0,845$ & 0,429 & $(0,752)$ \\
\hline Laki-laki & 0,053 & 1,054 & $(0,658)$ \\
\hline Bagian jantung \& paru & $3,346^{* * *}$ & 28,403 & $(0,709)$ \\
\hline Konstanta & $-3,358^{* * *}$ & 0,5 & $(1,044)$ \\
\hline $\begin{array}{l}\mathrm{N} \\
\mathrm{R} 2 \\
\end{array}$ & & & \\
\hline
\end{tabular}

merokok $(81,2 \%)$, dan hanya sekitar $2,1 \%$ dokter tersebut yang merokok setiap hari. Responden berumur 60 tahun ke atas $(33,7 \%)$ dan berpengalaman praktik 20 tahun atau lebih $(38,5 \%)$. Responden yang bekerja di bagian penyakit dalam $(52,1 \%)$, berpendidikan magister atau spesialis $(53,1 \%)$, dan melayani pasien rata-rata lebih 20 orang per hari $(56,2 \%)$ (Lihat Tabel 1$)$.

\section{Pengetahuan, Sikap, dan Praktik Dokter Terkait Merokok}

Dokter yang mengetahui bahwa perokok pasif berdampak pada kesehatan $(93,8 \%)$ dan kadar tar/nikotine rendah dalam rokok berbahaya bagi kesehatan $(84,4 \%)$ tergolong tinggi (Lihat Tabel 2). Hampir seluruh responden $(93,8 \%)$ setuju menjadikan dokter sebagai role model perilaku tidak merokok dan $95,8 \%$ setuju memperluas area bebas asap rokok ke seluruh kawasan rumah sakit. Namun, sekitar $66,7 \%$ dokter tidak selalu bertanya tentang kebiasaan merokok pasien dan sekitar 38\% dokter tidak selalu memberikan nasehat untuk berhenti merokok kepada pasien yang merokok (Lihat Tabel 2).

\section{Prediktor Dokter yang Bertanya Status Merokok Pasien}

Untuk menguji hubungan antara kebiasaan dokter menanyakan status merokok pasien dengan 6 kovariat, yaitu pengalaman kerja, pendidikan, jumlah pasien per hari, status merokok dokter, jender, dan bagian tempat praktik dokter, dilakukan analisis regresi logistik. Ditemukan bahwa bagian tempat praktik dokter adalah satu-satunya variabel yang berhubungan bermakna ( $\mathrm{p}$ value $=0,001, \mathrm{OR}=28,4)$. Dokter yang berpraktik di bagian jantung dan paru berpeluang 28,4 kali lebih besar untuk menanyakan status merokok pasien daripada yang berpraktik di bagian penyakit dalam (Lihat Tabel 3). 


\section{Pembahasan}

\section{Keterbatasan Penelitian}

Angka keberhasilan pengumpulan data dalam survei ini hanya mencapai $60 \%$, yaitu dari 161 dokter yang diminta kesediaannya hanya 96 yang bersedia diwawancarai. Diantara dokter yang tidak bersedia mungkin memiliki pengetahuan, sikap, dan pola perilaku merokok yang berbeda daripada mereka yang bersedia menjadi responden. Oleh sebab itu, generalisasi atas hasil survei ini harus dilakukan dengan hati-hati.

Prevalensi dokter responden yang merokok hanya $3,1 \%$ yang jauh lebih rendah daripada hasil studi di China $(23 \%)$ dan relatif sama di Amerika $(3,3 \%)$, Inggris $(6,8 \%)$, dan Hongkong $(4,3 \%){ }^{3}$ Hal tersebut tidak mengherankan karena pada studi ini dokter yang dipilih hanya dari jenis spesialisasi yang terkait dengan penyakit yang disebabkan oleh asap rokok, meliputi spesialis paru, spesialis jantung, dan spesialis penyakit dalam. Selain itu, calon responden dari spesialis yang sama yang menolak diwawancarai mungkin berperilaku berbeda. Studi di China mencakup dokter umum dan dokter spesialis lain. Namun, secara umum prevalensi perokok di China $(31 \%)$ lebih tinggi daripada di Indonesia $(23,7 \%)$.

Prevalensi dokter perokok penting mengingat perilaku dokter akan berpengaruh pada pasien. Nasehat untuk berhenti merokok dan konseling anti-merokok lebih mungkin diberikan oleh dokter yang tidak merokok daripada oleh dokter yang merokok. 3,6 Dengan demikian, menurunkan prevalensi dokter perokok merupakan faktor penting mengendalikan jumlah perokok. Hal ini berimplikasi pada perlunya dimulai pendidikan dokter yang bebas rokok, artinya mahasiswa kedokteran harus mempunyai komitmen untuk tidak merokok. Selain itu, rekrutmen dokter juga harus mempertimbangkan status merokok yang bersangkutan. Jika hal itu bisa dilakukan maka ada harapan bahwa dimasa depan prevalensi dokter perokok akan menurun dan bersamaan dengan itu praktik henti merokok akan meningkat dari hasil peningkatan nasehat dan konseling anti merokok yang dipraktikkan dokter di ruang kliniknya.

Dua per tiga dokter tidak selalu menanyakan status merokok pasien. Terlepas dari status merokok dokter, kewajiban dokter mengidentifikasi faktor risiko sakit pasien. Merokok merupakan faktor risiko berbagai penyakit. Jika dokter mengetahui faktor risiko yang ada dalam diri pasiennya, maka seorang dokter harus memberitahu dan mendorong agar pasiennya menghindari faktor risiko tersebut. Ketiga kelompok dokter spesialis yang paling dekat menangani organ pernapasan tidak selalu melakukan prosedur bertanya tentang status merokok pasien. Sangat mungkin keadaan kelompok dokter lain lebih buruk. Untuk mengatasi hal tersebut, disarankan pada masa praktik klinik mahasiswa kedokteran ditekankan selalu bertanya tentang status merokok pasien. Dengan praktik mengulang secara sinambung semasa menjadi mahasiswa kedokteran maka diharapkan secara otomatis dilakukan ketika sudah berpraktik sebagai dokter.

Sepertiga dokter yang mengetahui bahwa pasiennya merokok tidak selalu memberi nasehat berhenti merokok. Hal tersebut merupakan perilaku atau bukti bahwa dokter praktik di Indonesia tidak secara komprehensif terfokus pada kesehatan pasien. Padahal, sumpah dokter mengharuskan mengutamakan kepentingan pasien daripada kepentingan diri sendiri. Agar pasien terbebas dari penyakit atau untuk mencegah penyakit bertambah berat, dokter menasehati agar pasien tidak lagi merokok.

Ternyata hanya dokter paru dan jantung yang mempunya kebiasaan bertanya status merokok pasien. Pengalaman praktik, pendidikan, jumlah pasien, status merokok, dan jender tidak berhubungan. Hal ini membuktikan bahwa pendidikan dan kesadaran tugas, yang seringkali berhubungan dengan penyakit akibat rokok, telah membuat dokter berperilaku berbeda dari dokter di tempat lain. Ini bukti bahwa pendidikan dan pengetahuan yang terpajan terus-menerus dapat mengubah perila$\mathrm{ku}$. Indonesia surga pabrik rokok dan pemerintah belum berani menanda-tangani Framework Convention on Tobacco Control (FCTC). Dalam kondisi pemerintah Indonesia takut miskin karena kehilangan uang cukai rokok atau sudah terkolusi oleh beberapa perusahaan rokok (hanya ada 4 perusahaan yang menyumbang 95\% cukai rokok), maka satu-satunya harapan menyehatkan rakyat adalah mengubah perilaku rakyat. Dokter berperan penting mengubah perilaku rakyat. Jika saja, perila$\mathrm{ku}$ dokter dapat diubah, maka perilaku negatif pemerintah mengatasi bahaya merokok akan dapat dikompensasi.

Selain perilaku dokter, upaya massal menyadarkan masyarakat hendaknya juga dilakukan berbagai pihak, termasuk menyadarkan pejabat pemerintah untuk bersama 168 negara lain, menandatangani, meratifikasi atau berkomitmen mengendalikan bahaya merokok, untuk kesehatan dan produktifitas penduduk. Biaya kesehatan akibat merokok jauh lebih besar daripada cukai yang diterima pemerintah. Di Inggris, merokok merupakan masalah kesehatan masyarakat tunggal yang terpenting dan untuk mengatasinya National Health Services (NHS) diperkirakan mengeluarkan biaya sebesar 1,5 miliar Poundsterling per tahun. ${ }^{7}$

\section{Kesimpulan}

Prevalensi dokter paru, spesialis jantung, dan spesialis penyakit dalam di Jakarta yang merokok setiap hari sangat rendah yaitu hanya $2,1 \%$. Secara umum pengetahuan dan sikap dokter terkait merokok adalah baik, tetapi praktik di klinik yang terkait merokok masih tidak baik. Dokter tidak selalu bertanya tentang status 
merokok pasien. Berdasarkan analisis regresi logistik menemukan hanya bagian tempat kerja dokter merupakan variabel yang berhubungan signifikan. Dokter yang bekerja di bagian jantung dan paru berpeluang 28,4 kali untuk menanyakan status merokok pasien daripada dokter yang bekerja di bagian penyakit dalam.

\section{Saran}

Berdasarkan hasil studi disarankan memberikan kesempatan kepada dokter untuk mengakses informasi terbaru tentang bahaya kesehatan terkait dengan merokok, mempromosikan dokter sebagai role model perilaku tidak merokok. Hal tersebut merupakan strategi alternatif menekan jumlah perokok, dan mempromosikan kebiasaan dokter untuk bertanya tentang status merokok pasiennya dan menasehati mereka agar berhenti merokok. Selain itu, perlu mulai melaksanakan paradigma pendidikan kedokteran dan pelayanan kesehatan yang bebas rokok dengan merekrut mahasiswa kedokteran dan tenaga kesehatan yang tidak merokok.

\section{Ucapan Terima Kasih}

Studi ini terlaksana atas dukungan dana dari Publik Health Institute (PHI) sebagai koordinator Grant Research dari the National Institute of Health (NIH)
Fogarty International Center project Tobacco Control Policy Analysis and Intervention Evaluation.

\section{Daftar Pustaka}

1. Ng, Nawi, Weinehall L and Ohman A. If I don't smoke, i'm not a real man"-Indonesian teenage boys' views about smoking. Health Education Research. 2007; 22 (6 ): 794-804.

2. Badan Penelitian dan Pengembangan Kesehatan Departemen Kesehatan. Laporan nasional riset kesehatan dasar atau Riskesdas 2007. Jakarta: Departemen Kesehatan RI: 2009.

3. Jiang Y, Ong MK, Tong EK, Yang Y, Nan Y, Gan Q and Hu T. Chinese physicians and their smoking knowledge, attitudes, and practices. Am J Prev Med. 2007; 33(1): pg.15-22.

4. Masyarakat Peduli Bahaya Tembakau. Selamatkan generasi muda bangsa: segera ratifikasi konvensi pengendalian tembakau. Jakarta: 2008.

5. Chan S, Sarna SC, Linda W, David CN and Lam TH. Nurses' tobaccorelated KAP in four major cities in China. Journal of Nursing Scholarship. 2007. First Quarter; 39(1): pg.46-53.

6. Li, HZ, Fish D and Zhou X. Increase in cigarette smoking and decline of anti-smoking counseling among Chinese physicians: 1987-1996. Health Promotion International. 14 (2): pg.123-31.

7. Kmietowicz Z. Doctors told to treat nicotine addiction as a disease. British Medical Journal. 2000; (12) 320: pg. 397. 